\title{
Management of high inguinal undescended testis: a review of literature
}

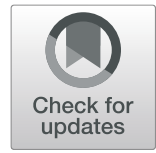

\author{
Shreyas K., Kirtikumar J. Rathod (D) and Arvind Sinha
}

\begin{abstract}
Background: Undescended testis is one of the most common paediatric surgical diagnoses. A lot of research has been done to date, to standardise the surgical management of intra-abdominal and extra-abdominal undescended testis. High inguinal undescended testis is a unique clinical encounter which demands additional surgical measures over conventional orchidopexy for better surgical results.

Main body of abstract: Open inguinal orchidopexy is a routine and quite straightforward operation for the majority of extra-abdominal undescended testis. However, there are instances in which the testis, even though situated in the inguinal region, poses a challenge for surgeons, to bring it in the scrotum by routine open inguinal orchiopexy. High inguinal testis can be defined as "any intra-canalicular testis present higher up in the inguinal canal and cannot be brought down easily to the scrotum by routine surgery as in standard orchiopexy (open or laparoscopy) and require additional lengthening manoeuvres". It needs additional surgical lengthening manoeuvres like Prentiss, along with the steps of routine orchiopexy to bring it down in the scrotum. This review article describes the various nomenclatures of undescended testis, appropriate investigations and also various additional surgical measures in the management of difficult high inguinal testis.

Conclusion: High inguinal undescended testis poses a unique technical challenge even to well-experienced surgeons. It is very important that surgeons dealing with this condition are well aware of the anatomy in this region and also various different manoeuvres described to date to bring the testis down in the scrotum.
\end{abstract}

Keywords: High inguinal testis, Difficult orchiopexy, Spermatic cord lengthening procedure

\section{Background}

Undescended testis is one of the most common paediatric surgical condition, and orchiopexy is a must-know operation for all paediatric surgeons and paediatric urologists. This usually straightforward standard operation can sometimes pose a difficult surgical challenge especially in cases of high inguinal testis. In this situation, routine inguinal orchiopexy fails to bring the testis down in the scrotum, and additional manoeuvres are required to achieve adequate length to do a tension-free orchiopexy.

* Correspondence: drkirtirathod@gmail.com; rathodkj@aiimsjodhpur.edu.in Department of Paediatric Surgery, All India Institute of Medical Sciences (AllM S), Jodhpur, India

(c) The Author(s). 2021 Open Access This article is licensed under a Creative Commons Attribution 4.0 International License, which permits use, sharing, adaptation, distribution and reproduction in any medium or format, as long as you give appropriate credit to the original author(s) and the source, provide a link to the Creative Commons licence, and indicate if changes were made. The images or other third party material in this article are included in the article's Creative Commons licence, unless indicated otherwise in a credit line to the material. If material is not included in the article's Creative Commons licence and your intended use is not permitted by statutory regulation or exceeds the permitted use, you will need to obtain permission directly from the copyright holder. To view a copy of this licence, visit http://creativecommons.org/licenses/by/4.0/. 
and can be treated conservatively. In contrast, a gliding testis is the one which can be manipulated into the upper scrotum but retracts when released [2].

UDT can be either congenital, meaning that the testis is absent in the scrotum since birth, or acquired, in which the testis was found and was recorded to be in the scrotum; however, it moved out of the scrotum in later life without any intervening inguinal surgery (in which it become iatrogenic).

Recurrent UDT means that the testis was extra scrotal at birth then it descends spontaneously but again becomes extra scrotal later in life [3]. Some surgeons also call it recurrent UDT, if the testis ascends again following a successful orchiopexy [4].

\section{Incidence}

UDT is one of the most common congenital anomalies, occurring in 2 to $8 \%$ of full-term and $33-45 \%$ of preterm or born underweight (birth weight $<2500 \mathrm{~g}$ ) infants [5]. The majority of the testes descend within the first 6 to 12 months such that the prevalence for boys aged 6 months to 1 year decreases to $1-2 \%[3,6]$.

\section{High inguinal testis}

The position of the testis in cases of cryptorchidism plays a pivotal role in surgical decision-making. UDT can be palpable in $70 \%$ of the cases; among the $20-30 \%$ of the impalpable cases [7], they are intra-abdominal and intra-canalicular or peeping testis in $50-60 \%$ of the cases, it is absent in $20 \%$ of the cases (monorchidism) and can be atrophic or rudimentary in $30 \%$ of the cases. Intra-canalicular testis is the testis which can be anywhere along the inguinal canal $[8,9]$.

High inguinal testis can be intra-canalicular or peeping testis, intra-canalicular testis is the one located between the internal and the external ring, and peeping testis or the high annular testis is the one that moves in and out of the internal ring [10]. High inguinal testis can be defined as "any intra-canalicular testis present higher up in the inguinal canal and cannot be brought down easily to the scrotum by routine surgery as in standard orchiopexy (open or laparoscopy) and requires additional lengthening manoeuvres". These high inguinal testes whether palpable or non-palpable pose a certain challenge in deciding the management particularly owing to the short length of the cord structures.

\section{Historical background of high inguinal undescended testis and lengthening procedures}

Ever since John Hunter described the mechanism of descent of testis in 1786, its surgical management was widely attempted across the globe; the first such attempt of orchiopexy was by J.F. Rosenmerkel of Munich in 1820 and M.J. Con Chelius in 1837 [11]. However, the first recorded attempt was performed by James Adams in the London Hospital in 1871. Thomas Annandale is a pioneer credited for the first successful relocation of the testis (orchiopexy) in a 3-year-old boy with an ectopic testis in 1879.

In 1881, Max Schuller, in the Annals of Anatomy and Surgery, described a surgical testis for undescended testis which, for the first time, emphasised the need for mobilisation of the spermatic cord, which today is a standard practice for high inguinal testis (Table 1). In 1893, Leonard Bidwell described a technique for inverting the testis to gain approximately an inch and a half of length and anchoring the testis to an external wire cage to provide continuous traction. In 1899, Arthur Dean Bevan advocated releasing the spermatic vessels up to the retroperitoneum and possible resection of them to gain length adequate enough to achieve a tension-free mobilisation of the testis to the scrotum.

Keetley (1894) and Torek (1909) independently reported the technique of fixation of the testis in the fascia lata for a period of 3 to 6 months and then detached carefully and repositioned in the scrotum to achieve possible lengthening of the cord. Cabot and Nesbit of Michigan University described the use of a rubber band and a wire cage for approximately 12 days for continuous traction. Robert J. Prentiss of San Diego popularised the

Table 1 Historical development in the management of undescended testis

\begin{tabular}{|c|c|c|}
\hline Pioneer & Concept & Year \\
\hline John Hunter & Mechanism of descent of the testis. & 1786 \\
\hline James Adams & First recorded attempt orchiopexy. & 1871 \\
\hline $\begin{array}{l}\text { Thomas } \\
\text { Annandale }\end{array}$ & First successful orchiopexy. & 1879 \\
\hline Max Schüller & $\begin{array}{l}\text { Division of the processus vaginalis to mobilise } \\
\text { the spermatic cord. }\end{array}$ & 1881 \\
\hline $\begin{array}{l}\text { Leonard } \\
\text { Bidwell }\end{array}$ & $\begin{array}{l}\text { Inverting the testis and anchoring the testis to } \\
\text { an external wire cage to provide continuous } \\
\text { traction. }\end{array}$ & 1893 \\
\hline $\begin{array}{l}\text { Arthur Dean } \\
\text { Bevan }\end{array}$ & $\begin{array}{l}\text { Tension-free mobilisation of the testis to the } \\
\text { scrotum by releasing the spermatic vessels of } \\
\text { retroperitoneum and possible resection. }\end{array}$ & 1899 \\
\hline $\begin{array}{l}\text { Keetley and } \\
\text { Torek }\end{array}$ & $\begin{array}{l}\text { Fixation of the testis in the fascia lata and } \\
\text { staged orchidopexy }\end{array}$ & $\begin{array}{l}1894 \\
1909\end{array}$ \\
\hline $\begin{array}{l}\text { Cabot and } \\
\text { Nesbit }\end{array}$ & $\begin{array}{l}\text { Fixation of the testis with a rubber band and a } \\
\text { wire cage for } 12 \text { days. }\end{array}$ & 1931 \\
\hline $\begin{array}{l}\text { Robert J. } \\
\text { Prentiss }\end{array}$ & $\begin{array}{l}\text { Division of the inferior epigastric vessels and } \\
\text { medial displacement of the spermatic vessels. }\end{array}$ & 1959 \\
\hline Schoemaker & Subdartos pouch fixation. & 1932 \\
\hline $\begin{array}{l}\text { Fowler and } \\
\text { Stephens }\end{array}$ & $\begin{array}{l}\text { Studied vascular anatomy of the testis gave the } \\
\text { concept of collateral circulation. }\end{array}$ & 1959 \\
\hline $\begin{array}{l}\text { Jones and } \\
\text { Bagley }\end{array}$ & High inguinal incision. & 1979 \\
\hline Bloom & Staged pelviscopic orchiopexy. & 1991 \\
\hline
\end{tabular}


famous Prentiss manoeuvre which involved the division of the inferior epigastric vessels and medial displacement of the spermatic vessels to achieve the lengthening of the cord.

Cortesi et al. first described laparoscopy as a modality to identify the location of non-palpable testis. The pure one-stage laparoscopic orchiopexy was first reported by Jordan and Winslow. Laparoscopy can be used in orchidopexy for either one-stage orchiopexy with preservation of spermatic vessels or Fowler and Stephens orchiopexy [11].

\section{Clinical examination}

Examination of the patient with high inguinal UDT is no different from the other variants and should essentially start from a thorough general physical examination to pick up the signs of associated or causative syndromes like Prader-Willi or Kallmann syndrome [12, 13].

Local examination of the genitalia includes a careful examination to look for any penile abnormalities, ambiguous genitalia, or redness or local erythema which may suggest acute testicular torsion if associated with pain. Evidence of concurrent hypospadias and ambiguous genitalia which are associated with mixed gonadal dysgenesis and true hermaphroditism should be noted during the inspection.

Palpation using a two-handed technique allows differentiation between palpable and non-palpable, retractile and gliding testes. The patient needs to be examined in both supine and standing positions. The examiner should adequately lubricate his or her hands with surgical lubricant, and one hand of the examiner should sweep along the inguinal canal starting from the anterior superior iliac spine down to the pubic tubercle. A true undescended testis and ectopic testis will be felt by examiners sliding fingers as a pop with this technique, while with the opposite hand, a low ectopic or retractile testis can be milked down to the scrotum. Once the testis is released, if it immediately springs out of the scrotum, it is mostly an ectopic testis, and if it remains in the scrotum for a certain while and then retracts back, it can be termed as a retractile testis [12,13].

Testis should be carefully examined for size, position and consistency, and compared with the opposite testis. Any palpable para testicular anomalies, the presence of hernia or hydrocele, should also be looked for as they may alter the line of management $[12,13]$.

\section{Investigations}

The role of imaging in the evaluation of undescended testis has always remained controversial and uncertain; however, it plays an important role in assessing the position of the testis and volume in comparison with the contralateral normal testis.
Ultrasonography (USG) is a non-invasive investigation and has other advantages like wide availability, low cost and good repeatability which makes it a commonly used imaging modality in the evaluation of UDT [14]. High inguinal undescended testis which remains inaccessible to physical examination can at times be picked up by USG. It is also a good tool to assess the size of the inguinal testis. However, the inter-observation variations, lack of predictive accuracy and less reliability in intraabdominal testis and reports of mislabelling a normal or retractile testis are its potential limitations [14].

Modern ultrasound with a high-resolution transducer $(>7.5 \mathrm{MHz})$ can measure three dimensions of both testes and can help in calculating testicular volume. The testicular atrophy index (TAI) of the affected testicle can then be calculated as TAI $(\%)=($ contralateral TV - affected TV)/contralateral TV $\times 100 \%$ [15]. A testicular atrophy index of less than $20 \%$ is suggested as an indication for doing orchiopexy in the case of older boys with retractile testis [16]. Also, Niedzielski et al. studied 105 cryptorchid boys, aged 1 to 15 years, who underwent unilateral orchiopexy, and TAI was calculated before and 1 year after surgery and concluded that there was a significant difference in TAI values, ranging from 18.16 to $36.43 \%$ in boys between 2 and 10 years $(p<0.001)$. In the youngest $(0-2$ years) and the oldest ( $>10$ years) boys, the difference was not statistically significant.

Computed tomography $(\mathrm{CT})$ is selectively used as a diagnostic modality in UDT, more so in bilateral impalpable testis [17]. The risk of exposure to radiations in a pre-setting of malignancy risk in cases of UDT need for sedation or general anaesthesia limits its use in the routine evaluation of these patients [17].

Magnetic resonance imaging (MRI) is the least invasive although an expensive tool in the evaluation of UDT [18]. Conventional magnetic resonance imaging can pick up with moderate specificity an absent testis, but it lacks sensitivity in identifying the presence of impalpable testis. Its role in locating the atrophic testis is also limited. Advanced modalities like diffusionweighted imaging added to conventional MRI is proposed to increase the sensitivity and accuracy in the detection of non-palpable testes [18]. However, the requirement of general anaesthesia usually in younger children limits its use. Magnetic resonance venography and angiography allow visualisation of the spermatic vessels and the pampiniform plexus, which can help in the identification of a viable or vanishing testis [19]. Some authors propose using this modality to avoid diagnostic laparoscopy when this imaging demonstrates an intracanalicular viable or vanishing testis. Another proposal is to adopt a non-surgical approach when this modality detects a testicular nubbin. These observations are however contraindicated by other studies thus making its 
usage debatable [19]. Additionally, this modality is also invasive, difficult to perform and has a high rate of complication [19].

To conclude, the potential indications of different imaging modalities for UDT are limited and are extremely specific as in the identification of Mullerian structures in cases with suspicion of disorders of sexual differentiations (DSD) or for determination of exact testicular size if needed.

\section{When to operate}

The appropriate age for orchidopexy has always remained a matter of debate and has evolved with clarity in our understanding of the etiopathogenesis of undescended testis [20]. From the age of $10-15$ years recommended for orchidopexy in the 1950s and 5-6 years in the 1970s, the current recommendation stands at the age between 6 and 18 months of life. Early orchiopexy is believed to prevent impaired spermatogenesis and malignancy in adult life [20].

The surgical options for intra-canalicular testis include inguinal orchiopexy, trans-scrotal orchidopexy, laparoscopic-assisted inguinal approach and various cord lengthening methods.

\section{Inguinal orchiopexy}

It involves a low transverse inguinal crease incision along the Langer lines and deepening in layers. Once the external ring is found, the external oblique fascia is incised to expose the canal, with care taken to avoid injury to the ilioinguinal nerve [8]. The spermatic cord is isolated, and distally, the testis is dissected from its attachment to the gubernacular remnant. Care should be taken to avoid injury to the long-looped vas deferens if at all present. The hernial sac is identified and the sac is opened overlying the testis, and the incision is extended proximally along the length of the cord. The sac is ligated at the level of the deep ring, and the cord structures are further gently separated from the sac after its ligation. Then, a transverse scrotal incision should be given for the creation of subdartos pouch. The subcutaneous tunnel is created anterior to the pubis using a large clamp or a finger through which the testis is delivered to the scrotum. It should be ensured that there is no twisting of the spermatic cord and all the testicular appendages are excised. Closure of the opening in the dartos around the cord with tunica vaginalis will ensure fixation of the testis in the subdartos pouch. Fixing the tunica albuginea to the scrotal wall is also documented but one should be mindful of the risk of injury to the testis by inflammatory or vascular insult by such fixation. However, in some cases where the cord length remains relatively short despite lengthening manoeuvres, such fixation will be required to achieve the desired outcome of the orchidopexy. This approach coupled with methods of lengthening the cord structures can ensure successful orchiopexy in high inguinal testis.

\section{Trans-scrotal orchiopexy}

A primary trans-scrotal approach of orchidopexy is reserved primarily for palpable undescended testis which is either close to the scrotum or can be brought down to the scrotum and thus is of limited significance in high inguinal testis [8]. High scrotal, transverse lower scrotal and mid-scrotal incisions are described. Once the testis is delivered out of the incision, the distal sac with cremaster is mobilised proximally. Sometimes, an additional inguinal incision might be required in difficult cases for further lengthening of the cord and for the ligation of the sac.

\section{Cord lengthening procedures}

Orchidopexy aims at bringing the testis to the mid scrotum without any damage to the vas and the vessels and with minimal or no tension on the pedicle. In cases of a high inguinal testis, after inguinal orchidopexy, the testis can be brought up to the high scrotal level or the superficial inguinal pouch and sometimes up to the midscrotum. However, many times this is associated with additional tension in the cord and the vessels carrying the risk of atrophy and retraction.

Multiple operative manoeuvres are reported to gain the length of the cord structures without any components of tension. These include the retroperitoneal mobilisation, division of lateral fibrous bands, Prentiss manoeuvre, modified Prentiss manoeuvre, pre-peritoneal approach and microvascular surgery.

\section{Retroperitoneal mobilisation and division of lateral fibrous bands}

On reaching the deep ring as in inguinal orchiopexy, if the mobilised cord structures are short, so as to reach the mid-scrotal level and further lengthening is needed, it can be obtained by opening the internal ring by dividing the internal oblique fibres and by dividing the fibrous bands that run laterally from the cord to the abdominal wall within the deep ring (Figs. 1 and 2). This along with further mobilisation of the cord structures retroperitoneally, sometimes even up to the level of kidney, will aid in achieving adequate length of the cord structures [21]. In our experience of 2 cases of high inguinal testis, we have done this retroperitoneal mobilisation successfully with laparoscopy.

\section{Prentiss manoeuvre}

In some cases of high inguinal testis even after the complete retroperitoneal mobilisation, the length of the spermatic cord is still inadequate, the Prentiss manoeuvre, 


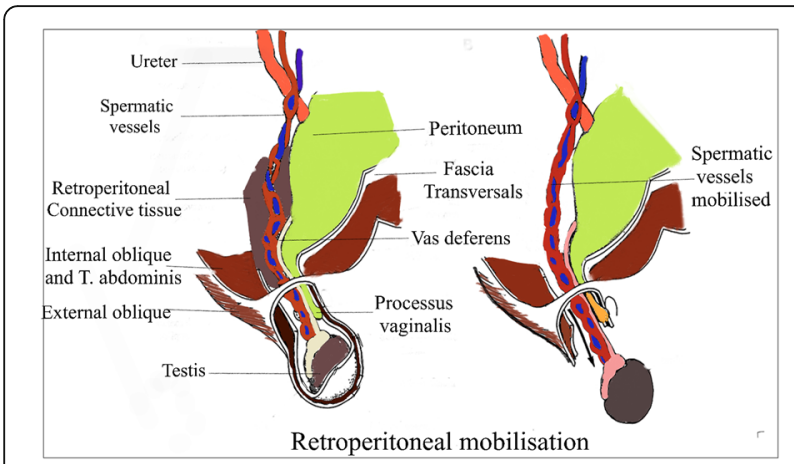

Fig. 1 Retroperitoneal mobilisation

which involves dividing the inferior epigastric vessels and bringing the spermatic cord medially, to provide a straight, and a shorter course to the scrotum can be considered as an option [8] (Fig. 3).

The original technique described by Prentiss involved the standard inguinal orchidopexy coupled with an incision at the level of the deep ring which includes the internal oblique muscle lateral to the internal ring, division of the fascia transversalis and the inferior epigastric vessels in the floor of the inguinal canal. Following this development of the retroperitoneal space is done up to the kidney as previously described. The cord structures can be elevated from the posterior retroperitoneum with gentle dissection. This step can be done by infiltration of saline in the space between the retroperitoneum and vessels thus doing hydro-dissection. Division of the lateral spermatic ligament allows the medial and the posterior mobilisation of the spermatic vessels and hence the gaining some length of the vessels.

Some of the limitations in the Prentiss manoeuvre include the incision of the transversalis fascia up to the renal lodge for re-routing of intra-abdominal testes, which seems unnecessary with the current use of

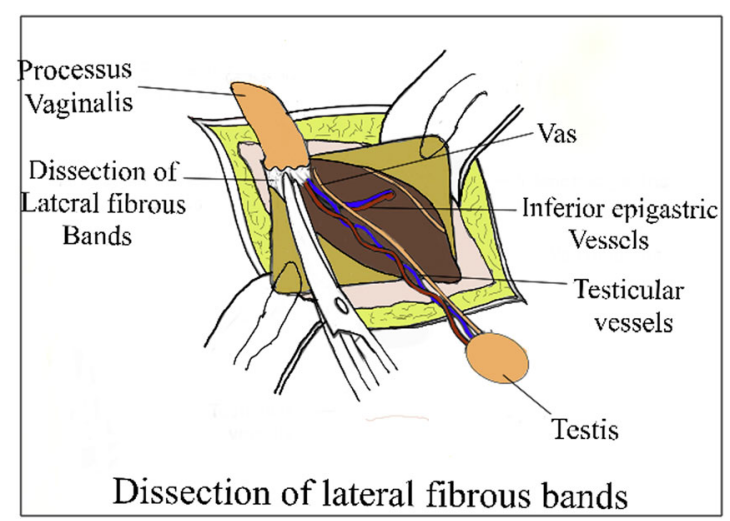

Fig. 2 Division of lateral bands laparoscopic techniques for non-palpable testicles. Also, it involves the ligation of the inferior epigastric vessels (IEV). Ligation of the IEV might cause vascular compromise for the rectus muscle and posterior rectus sheath resulting in muscular hypotrophy, impaired healing of lower midline laparotomy, impossibility of further harvesting of the rectus abdominis muscle flap, and loss of internal thoracic artery-internal epigastric artery collateral pathway in patients with aortoiliac occlusion [8].

\section{Modified Prentiss manoeuvre}

A modification of the Prentiss manoeuvre is suggested in which the inferior epigastric vessels are not divided [22]. The principle is that the testis is just routed through a shorter path medial to inferior epigastric vessels. In this procedure, after an inguinal skin crease incision, the external oblique fibres are divided. Then, the processus and tunica vaginalis are identified and are dissected free from the cremasteric fibres. The gubernaculum at the lower pole is divided. The cord structures are mobilised as previously described up to the deep ring; the deep ring is then opened laterally followed by retroperitoneal dissection.

A small opening resembling a buttonhole is made in the transversalis fascia above the pubic tubercle. Artery forceps is passed through it behind the fascia so that its tip emerges out of the deep ring.

The testis is then held by its tunica using a forceps and is pulled along with the forceps behind the fascia transversalis and out of the opening created. It is then brought down to the scrotum without any tension. The deep ring is approximated followed by external oblique repair (Fig. 4).

This technique offers specific advantages like permitting tension-free placement of the testis in the scrotum, preservation of the integrity of the posterior wall of the inguinal canal and inferior epigastric vessels unlike the Prentiss manoeuvre, safeguarding against the retraction of the testis owing to the buttonhole effect of a small opening [22].

\section{Distal spermatic cord peritoneal stripping: an adjunct technique during inguinal orchiopexy}

This method involves a transverse inguinal incision, standard inguinal dissection and mobilisation of the peritoneal reflection at the level of the deep ring and other cord length increasing manoeuvre. If an additional length of the cord is needed, then dissection and stripping of the peritoneal investments of the distal spermatic cord are done taking care while dissecting at the level of epididymis [23]. 


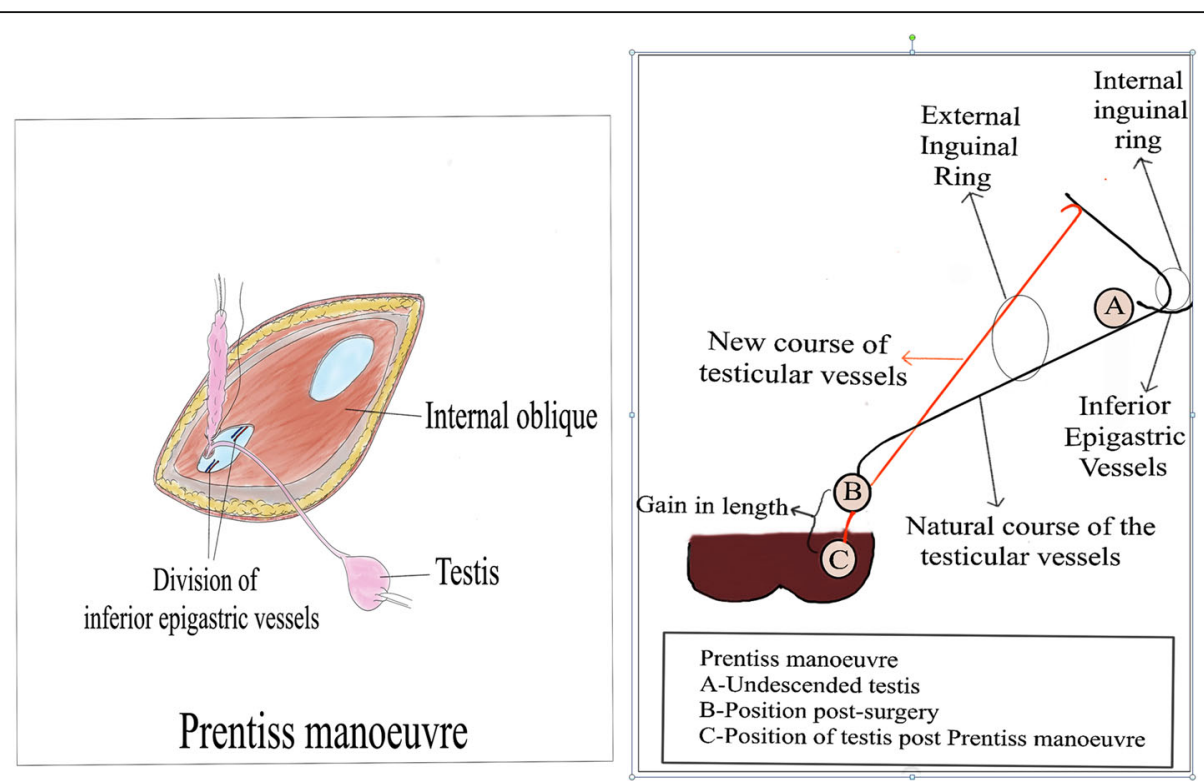

Fig. 3 Prentiss manoeuvre and straight route of the testis after Prentiss manoeuvre in a right undescended testis

\section{Micro-vascular anastomosis technique}

This technique involves an inguinal crease incision which shall be extended in layers to reach the internal ring. An intra-peritoneal or retroperitoneal approach can be decided based on the position of the testis. The testicular vessels need to be identified and dissected free of the surrounding structures reaching up to the level of the lower pole of the kidney. Then, the epigastric vessels are identified and are dissected free of surrounding

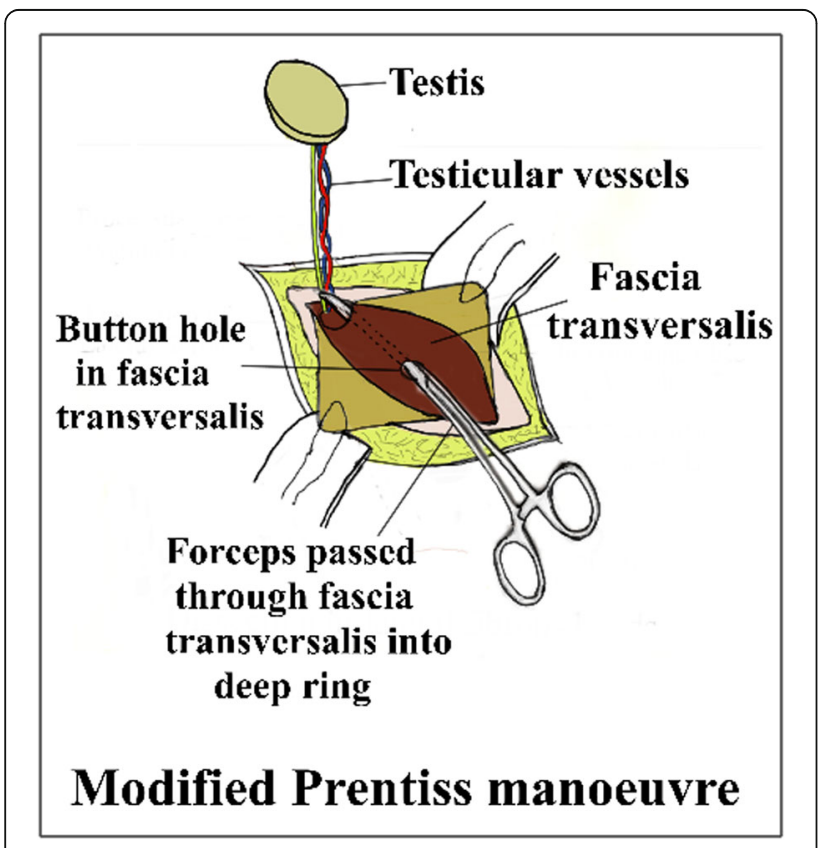

Fig. 4 Modified Prentiss manoeuvre structures-usually under an operating microscope. The testicular vessels can then be divided higher up and ligated proximally. The testicular artery and the veins are then anastomosed respectively with the inferior epigastric artery and the vein under a microscope without any tension with or without spatulation at the end of the vessel depending on the disparity in diameter between the two vessels (Fig. 5). Arterial anastomosis should be done at first to limit the possibility of ischaemia. The testis with gained length of vessels can now be brought into the subdartos pouch and fixed in the method previously described $[24,25]$.

\section{Role of laparoscopy}

Laparoscopic orchiopexy in peeping testis High inguinal testis can sometimes be easily managed by gaining cord length by laparoscopic dissection. A standard laparoscopic technique is to be followed with a $5-\mathrm{mm}$ umbilical port as a camera port and two 5 - $\mathrm{mm}$ ports in the midclavicular line just below the level of the first port in the lumbar region to be inserted. The testis peeping from the internal ring can be visualised.

The peritoneum is dissected starting from a point lateral to the testicular vessels and extending to the internal ring and then medial to the vas deferens. The gubernaculum is then dissected. Adequate length of the cord structures is confirmed when testis can reach the contralateral internal ring.

The testicular vessels are mobilised up to the retroperitoneum to prevent unnecessary tension and vascular compromise. Subdartos pouch is then created as 


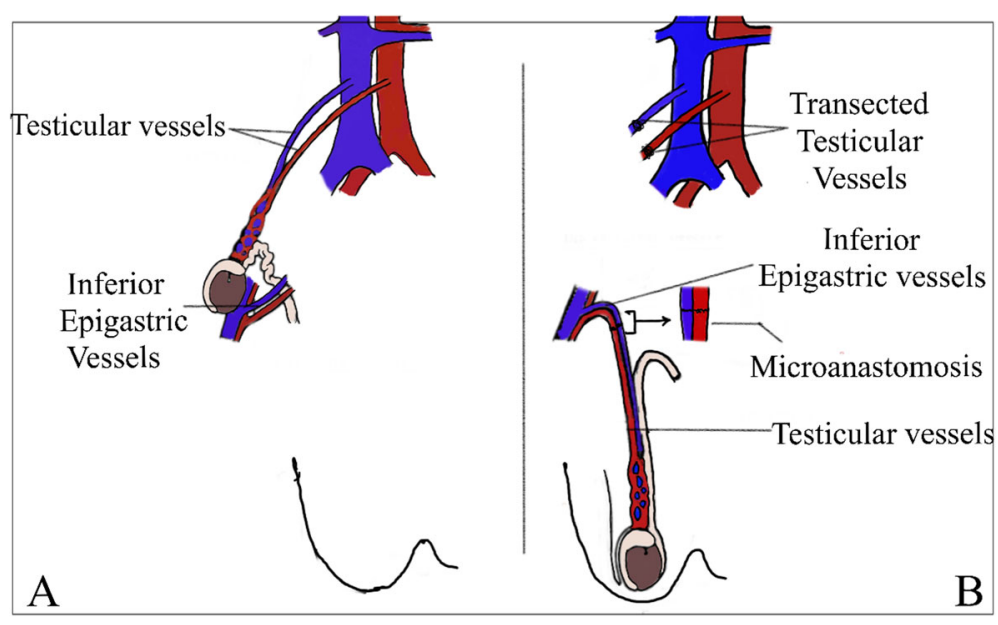

Fig. 5 Microsurgery and auto-transplantation

previously described, and the testis is mobilised downwards with forceps medial to inferior epigastric vessels to the subdartos pouch and fixed.

Some authors describe insertion of 8- or 10-mm trocar from the scrotum through the outer ring. A laparoscopic clamp passed through this can grasp the gubernaculum, and the testis can be delivered out with gentle twisting motion [26].

Ante-grade laparoscopic testicular vessels dissection The standard laparoscopic technique with port placement as previously described shall be adopted. The vas and the vessels should be identified which will be usually seen passing the internal ring. This is to be followed by ante-grade dissection in the inguinal canal both medially and laterally including dissection of testicular vessels with proximal mobilisation of gubernaculum if necessary. The testis is then brought to the abdomen at first, cord length assessed and passed to the scrotum through the canal under laparoscopic guidance. This technique adds additional measure to ensure the preservation of vas and the vessels and thus prevent vascular compromise of the testis [27].

Staged orchidopexy Two-stage orchidopexy can be considered when either of the vas or the gonadal vessels are short to reach the scrotum even after full mobilisation with lengthening procedures like Prentiss manoeuvre. The testis can be anchored in the distalmost position that can be achieved in the first surgery, and a second procedure can be done at or after 6 months [28]. Considering staged orchidopexy in this situation can be preferred over Stephen-Fowlers orchidopexy as the initial lengthening manoeuvres like retroperitoneal mobilisation can potentially cause division of many of the collateral vessels upon which the success of the procedure depends [29]. However, like any secondstage procedure, the presence of adhesions around the testis and the internal ring poses a challenge to surgeons and carries a risk of injury to the gonadal vessels and the vas $[30,31]$.

Lasheen spiral spring Lasheen described the use of a spiral spring for lengthening the spermatic cord, based on tissue expansion theory. This technique involves the use of a spiral ring prepared from fine steel wire. The distance between each rotation of spiral spring being 0.5 $\mathrm{cm}$, its length corresponds to the distance between the internal inguinal ring and the bottom of the scrotum, and the diameter is equal to the diameter of the spermatic cord. The procedure involves a standard inguinal crease incision followed by the dissection of the testis and the spermatic cord and excision of the hernial sac, if any. The appropriate spring will be put in the right position, from the testicular spermatic cord end, by clockwise rotation, until it reaches the internal inguinal ring. The presence of Lasheen spiral spring produces fine continuous pouching force on the testis and cord toward the bottom of the scrotum. This will be followed by the closure of the inguinal wound. The proximal spring end appears and is fixed by one stitch on inguinal skin. After achieving adequate lengthening of the spermatic cord (ranging from 3 to 4 weeks or even more in high inguinal testis), the spiral spring will be removed, by application of fine traction with clockwise rotation on the proximal end of spring under light sedation [32].

Abdominal pre-peritoneal approach This technique was originally described by Jones and Bagley in 1979 [21]. This involves a standard inguinal exploration to reach the external oblique aponeurosis. Once the 
aponeurosis is opened, a "step-ladder" parallel musclesplitting incision through the internal oblique and the transversalis muscles is made, $3-4 \mathrm{~cm}$ above the inguinal canal, thus reaching the extraperitoneal space above the region of the internal inguinal ring, where the testis is frequently found. The vas and the blood vessels, in their separate course at this level, are mobilised which allows the dissection to a much higher level. The testis is drawn down to the scrotum similar to the Prentiss manoeuvre. If the testis is not found at this level, the adjacent peritoneum can be opened and the peritoneal cavity is explored. This approach provides a greater access to provide adequate length to the cord structures and to allow tension-free placement of the testis in the subdartos pouch within the scrotum [33].

Transfixing the testis to a nylon button for undescended testes with short spermatic cord This technique, a modification of the subdartos pouch technique, involves the fixation of the mobilised testis to a nylon button placed outside the scrotal skin and thus aims to retain the testis in the scrotum after orchidopexy in cases when there is a short spermatic cord. This technique involves steps of standard orchidopexy and lengthening techniques, in mobilising the cord structures and bringing the testis down to the subdartos pouch. The testis is then brought out through the scrotal incision and trans-fixed to a sterilised nylon button placed outside the scrotal skin, by 5-0 polypropylene suture with a round body needle. Inguinal and scrotal incisions are then closed. The button is kept for 7-18 days and removed once the scrotum bulges out (in contrast to the puckered appearing scrotum at the time of surgery) and when the testis can be moved from side to side [34].

Staged orchiopexy preserving spermatic vessels-using polytetrafluoroethylene pericardial membrane Although not in current practice, staged orchiorrhaphy was proposed by Michael et al. in 1975 [35], and staged procedures are considered across the world in many cases of difficult orchiopexy. This technique proposed by Dessanti et al. involves a 2-stage inguinal orchiopexy for intra-abdominal testis or testis peeping through the internal ring and short spermatic vessels. In this technique, the spermatic vessels are not sectioned but are lengthened through progressive traction of the spermatic cord, wrapped in polytetrafluoroethylene pericardial membrane. The first stage involves the mobilisation of the spermatic cord in the retroperitoneal space and wrapping it in the polytetrafluoroethylene membrane. The second stage, usually done after a period of 9-12 months, involves the removal of the polytetrafluoroethylene membrane [36].

\section{Conclusion}

Undescended testis is a common problem in the paediatric population which if persists for more than 6 months should be addressed surgically. The diagnosis is often made by the physical examination alone which may or may not be supplemented with diagnostic imaging modalities. Hormonal therapy is not a standard treatment for cryptorchidism and surgery-orchiopexy remains the treatment of choice with better success rates.

The mode and nature of the surgery depend on the position of the testis, and high inguinal testis poses a particular challenge to surgeons. Routine inguinal or scrotal orchidopexy will result in fixation of the testis in scrotum under tension thus leading to secondary atrophy or retraction of the testis. The use of laparoscopy is well established in the intra-abdominal testis however might not always help in high inguinal testis. Thus, comes the role of cord lengthening manoeuvres like the one described by Prentiss which adds to the length of the cord and prevent unnecessary tension on the cord structures. Other conditions like retractile testis can be followed up until puberty with 6 months yearly ultrasonic evaluation to look for testicular volume which if found decreasing prompts for a surgical treatment.

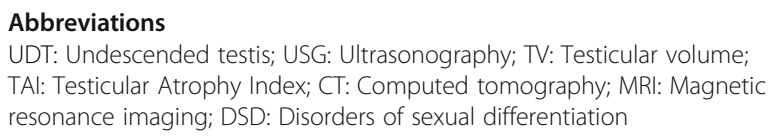

\section{Acknowledgements}

Not applicable

\section{Authors' contributions}

SK has drawn all the surgical diagrams and written the background and basis of the paper. KR and AS are senior authors who did the literature review, described the techniques of orchiopexy in simple ways and wrote the manuscript. All authors have read and approved the final manuscript.

Funding

None

Availability of data and materials Not applicable

Ethics approval and consent to participate

Not applicable

Consent for publication

Not applicable

Competing interests

The authors declare that they have no competing interests.

Received: 24 July 2020 Accepted: 3 June 2021

Published online: 21 September 2021

\section{References}

1. Ramareddy RS, Alladi A, Siddappa OS. Ectopic testis in children: experience with seven cases. J Pediatr Surg. 2013;48(3):538-41. https://doi.org/10.1016/j. jpedsurg.2012.10.005.

2. Ferro F, Lais A, Matarazzo E, Capozza N, Caione P. Retractile testis and gliding testis. Two distinct clinical entities. Minerva Urol Nefrol. 1996;48(3): 145-9. 
3. Barthold JS, González R. The epidemiology of congenital cryptorchidism, testicular ascent and orchiopexy. J Urol. 2003;170(6 Pt 1):2396-401. https:// doi.org/10.1097/01.ju.0000095793.04232.d8.

4. Noseworthy J. Recurrent undescended testes. Semin Pediatr Surg. 2003; 12(2):90-3. https://doi.org/10.1016/s1055-8586(02)00017-3.

5. Virtanen HE, Bjerknes R, Cortes D, Jørgensen N, Rajpert-De Meyts E, Thorsson AV, et al. Cryptorchidism: classification, prevalence and long-term consequences. Acta Paediatr. 2007;96(5):611-6. https://doi.org/10.1111/j.1 651-2227.2007.00241.x

6. Viljoen JT, Zarrabi A, Van der Merwe A. Management of cryptorchidism in adolescent and adult males. Afr J Urol. 2020;26(1):40. https://doi.org/10.11 86/s12301-020-00051-8.

7. Papparella A, Parmeggiani P, Cobellis G, Mastroianni L, Stranieri G, Pappalepore N, et al. Laparoscopic management of non palpable testes: a multicenter study of the Italian society of videosurgery in infancy. J Pediat Surg. 2005;40(4):696-700. https://doi.org/10.1016/j.jpedsurg.2005.01.010.

8. Radmayr C, Dogan HS, Hoebeke P, Kocvara R, Nijman R, Silay S, et al. Management of undescended testes: European Association of Urology/ European Society for Paediatric Urology Guidelines. J Pediatr Urol. 2016; 12(6):335-43. https://doi.org/10.1016/j.jpurol.2016.07.014.

9. Innocent MC, Asomugha LA, Ukamaka MN, Aronu ME. Ultrasound measured testicular volume in Nigerian adults: relationship of the three formulae with height, body weight, body-surface area, and body-mass index. Int J Adv Med Health Res. 2016;3(2):85-90. https://doi.org/10.4103/2349-4220.195940.

10. Hack WWM, Meijer RW, Bos SD, Haasnoot K. A new clinical classification for undescended testis. Scand J Urol Nephrol. 2003;37(1):43-7. https://doi.org/1 $0.1080 / 00365590310008686$.

11. Park K, Choi H. An evolution of orchiopexy: historical aspect. Korean J Urol. 2010;51(3):155-60. https://doi.org/10.4111/kju.2010.51.3.155.

12. Mau EE, Leonard MP. Practical approach to evaluating testicular status in infants and children. Can Fam Physician. 2017;63(6):432-5.

13. Docimo SG, Silver Rl, Cromie W. The undescended testicle: diagnosis and management. Am Fam Physician. 2000;62(9):2037-44 2047-8.

14. Jedrzejewski G, Wieczorek AP, Osemlak P, Nachulewicz P. The role of ultrasound in the management of undescended testes before and after orchidopexy - an update. Medicine. 2016;95(51):e5731. https://doi.org/10.1 097/MD.0000000000005731.

15. Niedzielski JK, Oszukowska E, Słowikowska-Hilczer J. Undescended testis current trends and guidelines: a review of the literature. Arch Med Sci. 2016; 12(3):667-77. https://doi.org/10.5114/aoms.2016.59940.

16. Niedzielski J, Pisarska K, Przewratil P. The usefulness of testicular atrophy index in the assessment of undescended testicle--preliminary report. Rocz Akad Med Bialymst. 2003:48:112-4.

17. Tasian GE, Copp HL, Baskin LS. Diagnostic imaging in cryptorchidism: utility, indications, and effectiveness. J Pediatr Surg. 2011;46(12):2406-13. https:// doi.org/10.1016/j.jpedsurg.2011.08.008.

18. Krishnaswami S, Fonnesbeck C, Penson D, McPheeters ML. Magnetic resonance imaging for locating nonpalpable undescended testicles: a meta-analysis. Pediatrics. 2013;131(6):e1908-16. https://doi.org/10.1542/ peds.2013-0073

19. Lam WW, Tam PK, Ai VH, Chan KL, Chan FL, Leong L. Using gadoliniuminfusion MR venography to show the impalpable testis in pediatric patients. AJR Am J Roentgenol. 2001;176(5):1221-6. https://doi.org/10.2214/ajr.176.5.1 761221

20. Chan E, Wayne C, Nasr A, FRCSC for Canadian Association of Pediatric Surgeon Evidence-Based Resource. Ideal timing of orchiopexy: a systematic review. Pediatr Surg Int. 2014;30(1):87-97. https://doi.org/10.1007/s00383013-3429-y.

21. Jones PF, Bagley FH. An abdominal extraperitoneal approach for the difficult orchidopexy. Br J Surg. 1979;66(1):14-8. https://doi.org/10.1002/ bjs. 1800660106.

22. Ayub K, Williams MP. A simple alternative technique of orchiopexy for high undescended testis. Ann R Coll Surg Engl. 1998;80(1):69-71.

23. Swana $H S$, Patel R, Rich MA. Distal spermatic cord peritoneal stripping: an adjunct technique during inguinal orchiopexy. Int Braz J Urol. 2015;41(3): 600-1; discussion 601. https://doi.org/10.1590/S1677-5538.

24. Garibyan H, Hazebroek FW, Schulkes JA, Molenaar JC, Dabhoiwala NF. Microvascular surgical orchiopexy in the treatment of high-lying undescended testes. Br J Urol. 1984;56(3):326-9. https://doi.org/10.1111/j.14 64-410X.1984.tb05398.X.
25. Bukowski TP, Wacksman J, Billmire DA, Sheldon CA. Testicular autotransplantation for the intra-abdominal testis. Microsurgery. 1995;16(5): 290-5.

26. Elderwy AA, Kurkar A, Abdel-Kader MS, Abolyosr A, Al-Hazmi H, Neel KF, et al. Laparoscopic versus open orchiopexy in the management of peeping testis: a multi-institutional prospective randomized study. Pediatr Urol. 2014; 10(4):605-9. https://doi.org/10.1016/j.jpurol.2014.06.006.

27. Shehata SM, Effat AMM, Shalaby MM. Ante-grade laparoscopic testicular vessels dissection in proximal inguinal undescended testis: a novel approach. JSM Pediatr Surg. 2018;2(2):1017.

28. Vikraman J, Hutson JM, Li R, Thorup J. The undescended testis: clinical management and scientific advances. Semin Pediatr Surg. 2016;25(4):241-8. https://doi.org/10.1053/.jsempedsurg.2016.05.007.

29. Kogan SJ, Houman BZ, Reda EF, Levitt SB. Orchiopexy of the high undescended testis by division of the spermatic vessels: a critical review of 38 selected transections. J Urol. 1989;141(6):1416-9. https://doi.org/10.1016/ S0022-5347(17)41330-9.

30. Corkery JJ. Staged orchiopexy - a new technique. J Pediatr Surg. 1975;10(4): 515-8. https://doi.org/10.1016/0022-3468(75)90194-3.

31. Steinhardt GF, Kroovand RL, Perlmutter AD. Orchiopexy: planned 2-stage technique. J Urol. 1985;133(3):434-5. https://doi.org/10.1016/S0022-5347(1 7)49009-4.

32. Lasheen AE. Lasheen technique for lengthening of spermatic cord in management cryptorchidism (Lasheen spiral spring). J Surg Surgical Res. 2020;6(1):038-40. https://doi.org/10.17352/2455-2968.000095.

33. Adam AS, Allaway AJ. The difficult orchiopexy: the value of the abdominal preperitoneal approach. BJU Int. 1999;83(3):290-3. https://doi.org/10.1046/ j.1464-410x.1999.00948.x.

34. Manoj S. Modified dartos pouch technique by transfixing the testis to a nylon button for undescended testes with short spermatic cord. GJRA. 2017;6(5).

35. Zer M. Staged orchiorrhaphy. Arch Surg. 1975;110(4):387-90. https://doi. org/10.1001/archsurg.1975.01360100029006.

36. Sampaio Francisco JB. Cryptorchidism with short spermatic vessels: staged orchiopexy preserving spermatic vessels. Int Braz J Urol. 2009:35(6):743-4. [cited 2020 Dec 14]. https://doi.org/10.1590/S1677-55382009000600021.

\section{Publisher's Note}

Springer Nature remains neutral with regard to jurisdictional claims in published maps and institutional affiliations.

\section{Submit your manuscript to a SpringerOpen ${ }^{\circ}$ journal and benefit from:}

- Convenient online submission

- Rigorous peer review

- Open access: articles freely available online

High visibility within the field

- Retaining the copyright to your article

Submit your next manuscript at $\boldsymbol{\nabla}$ springeropen.com 